\title{
Effects of Housing Condition, Feeding Style and Age on Meat Colour, and Some Carcass Characteristics in Eastern Anatolian Red Bulls
}

\author{
Sadrettin Yüksel ${ }^{1, a^{*}}$, Alpay Karaçuhalılar ${ }^{1, b}$, Fatma Yüksel ${ }^{1, c}$, Burcuhan Balta ${ }^{1, d}$ \\ ${ }^{l}$ Eastern Anatolian Agricultural Research Institute, 25240 Erzurum, Turkey
}

*Corresponding author

\section{A R T I C LE INFO}

Research Article

Received : 27/12/2018

Accepted : 10/04/2019

Keywords:

Feeding style

Housing condition

Carcass traits

Eastern Anatolian Red cattle

Carcass quality

\begin{abstract}
A B S T R A C T
This study was conducted to evaluate the muscles of the brisket region of the Eastern Anatolian Red (EAR) bulls in different ages subjected to different housing conditions and feeding style, and to determine the relationships among carcass traits, meat colour parameters and carcass measurements. Totally 25 bulls between 15 and $24 \mathrm{~m}$ of age were allocated to five groups (G1,G2,G3,G4,G5) according to feeding type, housing condition and age. The bulls were weighed fourteen days apart, feed consumption measurements were taken every morning, and slaughtered after 130 days of fattening. The differences were significant among G1-G3 for pelvic fat, total groups for conformation, among G1,G2-G3,G4,G5 for marbling, among G1,G2,G3-G4,G5 for LD area, among G1-G3,G5 for degree of fatten, among G1,G5-G2 for fat thickness over (LD) Longissimus Dorsi. The differences were significant in terms of meat colour parameters such as lightness $\left(\mathrm{L}^{*}\right)$ in G1,G2,G3-G4,G5 and hue value $\left(\mathrm{H}^{*}\right)$ in G1-G2,G3,G4,G5. Also, the differences among the groups are significant in terms of carcass length and width of the round. The correlation coefficients of carcass characteristic, colour score and conformation are negative with lightness $\left(\mathrm{L}^{*}\right)$ and yellowness ( $b^{*}$ ). Degree fatten had a positive correlation with marbling score. Conformation were positively correlated with carcass length. Carcass ribeye area and $\mathrm{L}^{*}$ showed a more desirable result in the G4 and G5 groups compared to other groups. Assessing the accumulated data of carcass traits with carcass components including carcass measurement during the slaughter or later phases of slaughter, it may be possible to use as a marker for the determining beef quality in EAR bulls.
\end{abstract}

\section{Introduction}

In the world, although production of all large meat types have been increasing in absolute terms, in relative terms the portion of global meat types have seen change significantly over the last years (Ritchie and Roser, 2018). Beef was also affected significantly from this change. Beef, which is an important part of meat production, has also been approximately $22 \%$ of total production by decreasing almost half in recent years (FAO, 2017). In order to avoid uncontrolled reductions in red meat, all parts of the carcass must be evaluated profitable. Generally, in beef carcass the round area (about 22-23\% of the total carcass) is more taken for evaluation, while the other parts (about $77-78 \%$ of the total carcass) are used as secondary products or process into by-product. This situation causes the becoming of red meat deficit and the increase of prices due to all parts of the carcass could not be evaluated efficiently. Recently, some parts (rib, loin) of this large mass have been preferred more than the muscles belonging the round region (Kukowski et al., 2004). Each part of the carcass is valuable in terms of red meat providing even if it has different structure. One of these important parts is brisket.

Brisket region is an indicator point in determining the condition score of a beef animal (Kunkle et al., 1994). Therefore, brisket and chuck areas should be considered in determining the adequacy of the application of fattening, the suitability of the animal and the fattening period. The muscles of this region, breed-specific, have a high characteristic both amount and consumption chance (Kryza, 2013).

Eastern Anatolian Red (EAR) is an important native cattle breed that had noticable brisket and chuck regions. This breed had been used as a power animal in the processing of agricultural land in the past, since it have large breast area. At the same time, this breed has high adaptation ability and able to evaluate marginal areas (Yüksel et al., 2011). However, there is still a lack 
information on different rearing styles and detailed carcass characteristic. Thence, this study is important in terms of the use in normal meat notion of muscles outside the round region muscles in red meat and determining the quality of these muscles and to determine the efficiency of the breed in different environmental conditions and the degree of carcass quality.

In the region, standard fattening system has generally not applied. For this reason, it is important to determine the carcass values under different rearing conditions for this breed and its rearer. This study is conducted to evaluate the muscles of the brisket region of EAR bulls in different ages subjected to different housing conditions and feeding style.

\section{Materials and Methods}

\section{Animal, Housing Conditions, Diet and Study Groups}

The study was carried out at The Eastern Anatolian Agricultural Research Institute, Erzurum, Turkey (at an altitude of $1.850 \mathrm{~m}$ above sea level), and 15 heads (24 m old) and 10 heads (12 m old) purebred EAR bulls were used. The study was conducted in February-June 2017. The animals were randomly assigned to five finishing models according to age, housing conditions, and feeding style. Three groups had been individually kept in pens size of $2 \times 2.20 \mathrm{~m}$ inside, and two groups had been kept in outside the barn. The pen size of $8 \times 21 \mathrm{~m}$ for $24 \mathrm{~m}$ old and $8 \times 15 \mathrm{~m}$ for $12 \mathrm{~m}$ old. The floor of pans are covered with concrete. The tempareture varied from 16 to $22^{\circ} \mathrm{C}$ inside, and from 2.2 to $-17^{\circ} \mathrm{C}$ outside. The bulls were divided into five groups and were fed on the diet given in chemical composition in Table 1. The adaptation period was two weeks. During this period, the animals consumed ad libitum the roughage and the same commercial concentrates. The experiment lasted for 130 days.

The following groups were set: Group1 (G1, in the individual pens inside) consisted of $24 \mathrm{~m}$ old bulls $(n=5)$ and fed once daily at 07:30 am. Group2 (G2, in the individual pens inside) consisted of $24 \mathrm{~m}$ bulls $(\mathrm{n}=5)$ and feed twice daily at 07:30 am and 3;30 pm. Group3 (G3, in the paddocks outside) consisted of 24 m old bulls $(n=5)$ and fed once daily at 07:30 am. Group4 (G4, in the individual pens inside) consisted of $12 \mathrm{~m}$ bulls $(\mathrm{n}=5)$ and fed once daily at 7:30 am. Group5 (G5, in the paddocks outside) consisted of $12 \mathrm{~m}$ old bulls and fed once daily at 7:30 am. All groups were offered ad libitum consumption of the rations with $40 \%$ roughage ( $40 \%$ alfalfa hay, $45 \%$ meadow hay, $15 \%$ wheat straw) and $60 \%$ concentrate $(20 \%$ barley, $20 \%$ wheat bran, $10 \%$ ground corn, $10 \%$ wheat, $8 \%$ cotton seed meal, $8 \%$ sunflower seed meal, $10 \%$ corn bran, $10 \%$ molasses, $2.5 \%$ ground limestone, and $1.5 \%$ salt on a dry matter basis) and clean water. Orts were collected prior to next feeding.

\section{Data Collection and Laboratory Analyses}

All bulls were fasted for $12 \mathrm{~h}$ and slaughtered at a stateowned abattoir to assess carcass quality. Carcasses were chilled for $24 \mathrm{~h}$ at $4^{\circ} \mathrm{C}$, after which the left sides were opened between the $12-13^{\text {th }}$ rib and the longissimus dorsi (LD) was used for quality of carcass according to the standard criteria guided by (USDA, 1989). The area of Longissimus Dorsi (LD) muscle cross section, the thickness of fat over the LD muscle, and a marbling score were determined at the ribbing site (USDA 1989). The pelvic fat was weighed, carcass conformation and degree of fatten were determined and some carcass measurements (carcass length, round length, width of the round) were taken. All carcasses were evaluated for yield grade by using a mathematical equation reported by Boggs and Merkel (1984). The meat samples from brisket region (Musculus pectoralis) were excised from the carcasses at 24-h post-mortem. The $\mathrm{pH}$ values were measured cut surfaces of brisket region by direct probe using a SCHOTT, Lab Star pH meter. Colour parameters were determined on brisket region $24 \mathrm{~h}$ after slaughter and after $30 \mathrm{~min}$ of exposure to the air. Minolta colorimeter device (CR-200, Minolta Co, Osaka, Japan) was used to objectively measure Commission Internationale I' E Clairage lightness (L*), redness $\left(\mathrm{a}^{*}\right)$ and yellowness $\left(\mathrm{b}^{*}\right)$, chroma values $(\mathrm{C})$, and hue value $(\mathrm{H})$ on the meat samples (Honikel, 1998). The scale used for marbling evaluation ranged from 1 to 6 (The scale used for marbling evaluation ranged from 1 to $6(1=$ slight, $2=$ small, $3=$ modest, $4=$ moderate, $5=$ slightly abundant, $6=$ abundant). The scale used for the degree of fatten $(1=$ low, $2=$ slight, $3=$ average, $4=$ high, $5=$ very high) and conformation $(1=$ poor, 2 = fair, $3=$ good, $4=$ very good, $5=$ extremely) evaluation ranged from 1 to 5 (USDA, 1989).

\section{Statistical Analysis}

The data of meat color, some carcass characteristics and carcass measurements were analysed using the General Linear Model procedure. The Duncan method was applied for comparison of subclass means when F-tests for main effects were significant. Correlation coefficients between the variables that follow different dispersion were determined by Dual Serie Correlation Method. In the statistical analysis was used package program (SPSS, 2015). The mathematical model in data analysis:

$$
Y_{i j}=\mu+A_{i}+e_{i j}
$$

$\mathrm{Y}_{\mathrm{ij}}$ : is the observation of age, housing condition, feding style, carcass and beef quality traits, $\mathrm{A}_{\mathrm{i}}$ : effect of treatment groups (i: G1,G2,G3,G4,G5), $\mathrm{e}_{\mathrm{ij}}$ : random error.

Table 1 Chemical composition of feeds used (DM basis)

\begin{tabular}{l|crrrrr}
\hline \multicolumn{1}{c|}{ Feed } & DM $(\%)$ & CP $(\%)$ & ME $(\mathrm{Mcal} / \mathrm{kg})$ & $\mathrm{CA}(\%)$ & ADF $(\%)$ & NDF $(\%)$ \\
\hline Alfalfa hay & 90.56 & 19.13 & 2.13 & 9.53 & 31.06 & 41.1 \\
Meadow hay & 92.26 & 10.13 & 2.10 & 8.9 & 39.55 & 62.4 \\
Wheat straw & 91.23 & 3.53 & 1.48 & 8.43 & 50.10 & 67.75 \\
Concentrate & 90.25 & 16.45 & 2.50 & 7.4 & - & - \\
\hline
\end{tabular}

DM: Dry matter; CP: crude protein; ME: metabolizable energy; CA: crude ash; ADF: Acid Detergent Fiber NDF: Neutral Fetergent Fiber 


\section{Results}

The carcass characteristics and measurements, and meat quality parameters are summarized in Table 2. Amount of pelvic fat in the animals slaughtered at the age of $24 \mathrm{~m}$ old was found higher than that of $12 \mathrm{~m}$ old animals $(\mathrm{P}<0.01)$. Except $\mathrm{G} 2$, amount of pelvic fat is significantly $(\mathrm{P}<0.01)$ higher in $\mathrm{G} 1(6.63 \mathrm{~kg})$ than the other groups. It was lower in the G5 in the study $(1.98 \mathrm{~kg})$. Similarly, the differences in the degree of fatten among the groups was significant $(\mathrm{P}<0.01)$. G1 had the highest ratio (3.40). In carcass conformation, G3 was found to be statistically different $(\mathrm{P}<0.01)$ from other groups and others were statistically similar. Animals with higher conformation scores had more free move, consequently, were housing more large area. The G3 has the highest score, is the lowest G4. The marbling score changed by the age and the feeding style $(\mathrm{P}<0.01)$, being the highest for the G1 group. The G3, G4 and G5 had similar marbling score, with structure of "small0" degree. There was a significant positive correlation $(0.632 * *)$ between the marbling score with the degree of fatten (Table 3 ).

Generally, groups with high marbling score and degree fatten found related to higher LD area in this study. The 24 $\mathrm{m}$ old bulls have a larger amount of LD area than $12 \mathrm{~m}$ old bulls $(\mathrm{P}<0.01)$. The G3 group had the highest LD area. In fat thickness, G2 was found to be high $(\mathrm{P}<0.01)$ from other groups and others were statistically similar. Yield grade values of the groups had different values numerically and these differences were not significant statistically $(\mathrm{P}>0.05)$. In the carcasses found yield grade range 1.191.94. Lower carcass yield grade (1.19) in all groups was reported in G3 bulls. The $\mathrm{pH}$ as well as meat colour parameters (except $L^{*}$ ) haven't significant differences among groups $(\mathrm{P}>0.05)$. A muscle $\mathrm{pH}$ range from 5.65 to 5.80 , and these range for $\mathrm{pH}$ was close to normal. High values of $\mathrm{pH}$ were observed in G1, G4 and G5 bulls, especially in G1 bulls, 5.80, 5.73 and 5.73 respectively.

Correlation coefficients for the carcass characteristics and measurements, meat quality parameters are summarized in table 3. Yield Grade is related with carcass components such as fat thickness, kidney, pelvic, and heart (KPH), hot carcass weight and LD area [yield grade had with fat thickness $\left(0.428^{*}\right)$, degree of fatten $\left(0.447^{*}\right)$, and LD area $\left.\left(-0.774^{* *}\right)\right]$. The highest coefficient of correlation $(0.281 *)$ was found between $\mathrm{pH}$ and colour yellowness (b*). There were not significant correlations between $24 \mathrm{~h}$ $\mathrm{pH}$ of meat and other colour characteristics were also ( $\mathrm{L}^{*}=$ $\left.-0.140, \quad \mathrm{a}^{*}=-0.009, \quad \mathrm{C}^{*}=0.046\right)$. Moderate negative correlations was observed between carcass conformation and the parameters of meat colour, except $\mathrm{H}^{*}$. There was a moderate relationships between hot carcass and conformation as well as $\mathrm{L}^{*}(0.553,-0.461$ respectively). Degree of fatten was correlated negatively in low degree with conformation and LD area $(-0.013,-0.122$ respectively). However, it was found significant medium level correlation with carcass length $\left(0.393^{*}\right)$.

There were differences among groups for carcass length $(\mathrm{P}<0.01)$ and width of the round $(\mathrm{P}<0.05)$, but not for length of round (Table 2).

\section{Discussion}

Attributes, such as colour and $\mathrm{pH}$, as well as basic carcass characteristics pelvic fat, degree of fatten conformation, marbling, LD area, fat thickness over LD, Yield Grade are important factors influencing meat characteristics.

Table 2 Pelvic fat weight, degree of fatten, conformation, marbling score, LD area, thickness of fat over the LD, yield grade, $\mathrm{pH}$, meat colour parameters and some carcass measurements and standard error

\begin{tabular}{|c|c|c|c|c|c|c|c|}
\hline \multirow{2}{*}{ Dependent Variable } & \multicolumn{5}{|c|}{ Groups $^{1}$} & \multirow{2}{*}{ SEM } & \multirow{2}{*}{ P-value } \\
\hline & G1 & $\mathrm{G} 2$ & G3 & G4 & G5 & & \\
\hline Pelvic fat weight, $\mathrm{kg}$ & $6.63^{\mathrm{a}}$ & $5.69^{\mathrm{ab}}$ & $4.93^{\mathrm{b}}$ & $2.72^{\mathrm{c}}$ & $1.98^{\mathrm{c}}$ & 0.54 & 0.000 \\
\hline Degree of fatten & $3.40^{\mathrm{a}}$ & $2.60^{\mathrm{ab}}$ & $2.16^{\mathrm{b}}$ & $2.60^{\mathrm{ab}}$ & $2.20^{\mathrm{b}}$ & 0.29 & 0.046 \\
\hline Conformation & $2.60^{\mathrm{b}}$ & $2.40^{\mathrm{bc}}$ & $3.66^{\mathrm{a}}$ & $1.60^{\mathrm{c}}$ & $2.60^{\mathrm{b}}$ & 0.31 & 0.002 \\
\hline Marbling & $5.00^{\mathrm{a}}$ & $3.80^{\mathrm{a}}$ & $2.50^{\mathrm{b}}$ & $2.00^{\mathrm{b}}$ & $2.00^{\mathrm{b}}$ & 0.41 & 0.000 \\
\hline $\mathrm{LD}$ area, $\mathrm{cm}^{2}$ & $68.83^{\mathrm{a}}$ & $67.10^{\mathrm{a}}$ & $73.72^{\mathrm{a}}$ & $48.88^{\mathrm{b}}$ & $54.19^{\mathrm{b}}$ & 4.21 & 0.001 \\
\hline Fat thickness over LD, mm & $3.10^{\mathrm{b}}$ & $4.30^{\mathrm{a}}$ & $2.58^{\mathrm{b}}$ & $3.58^{\mathrm{ab}}$ & $2.80^{\mathrm{b}}$ & 0.36 & 0.028 \\
\hline Yield Grade & 1.68 & 1.73 & 1.19 & 1.94 & 1.45 & 0.26 & 0.330 \\
\hline $\mathrm{pH}, 24 \mathrm{~h}$ & 5.80 & 5.65 & 5.69 & 5.73 & 5.73 & 0.03 & 0.092 \\
\hline \multicolumn{8}{|l|}{ Meat colour parameters } \\
\hline $\mathrm{L}^{*}$ & $39.93^{\mathrm{b}}$ & $39.26^{\mathrm{b}}$ & $38.83^{\mathrm{b}}$ & $42.23^{\mathrm{a}}$ & $43.02^{\mathrm{a}}$ & 0.55 & 0.000 \\
\hline$a^{*}$ & 20.67 & 20.44 & 20.19 & 20.95 & 19.95 & 0.43 & 0.501 \\
\hline$b^{*}$ & 4.61 & 5.26 & 5.41 & 5.12 & 5.64 & 0.34 & 0.300 \\
\hline $\mathrm{C}^{*}$ & 21.24 & 21.13 & 20.93 & 21.69 & 20.85 & 0.48 & 0.741 \\
\hline $\mathrm{H}^{*}$ & $5.58^{\mathrm{a}}$ & $4.10^{\mathrm{b}}$ & $3.90^{\mathrm{b}}$ & $4.18^{\mathrm{b}}$ & $3.79^{\mathrm{b}}$ & 0.34 & 0.002 \\
\hline \multicolumn{8}{|l|}{ Carcass measurement, $\mathrm{cm}$} \\
\hline Carcass length & $109.20^{\mathrm{a}}$ & $104.80^{\mathrm{ab}}$ & $109.00^{\mathrm{a}}$ & $100.60^{\mathrm{b}}$ & $102.60^{\mathrm{b}}$ & 1.74 & 0.005 \\
\hline Round length & 73.60 & 73.00 & 70.66 & 69.20 & 69.00 & 1.38 & 0.086 \\
\hline Width of the round & $22.20^{\mathrm{a}}$ & $22.00^{\mathrm{a}}$ & $21.66^{\mathrm{a}}$ & $20.40^{\mathrm{ab}}$ & $19.40^{\mathrm{b}}$ & 0.68 & 0.037 \\
\hline
\end{tabular}

${ }^{1}$ Group1 (G1, in the individual pens inside) consisted of 2-yr old bulls ( $\mathrm{n}=5$ ) and fed once daily at 07:30 am. Group2 (G2, in the individual pens inside) consisted of 2-yr bulls $(\mathrm{n}=5)$ and feed twice daily at 07:30 am and 3;30 pm. Group3 (G3, in the paddocks outside) consisted of 2-yr old bulls ( $\mathrm{n}=5$ ) and fed once daily at 07:30 am. Group4 (G4, in the individual pens inside) consisted of 1-yr bulls ( $\mathrm{n}=5$ ) and fed once daily at 7:30 am. Group5 (G5, in the paddocks outside) consisted of 1-yr old bulls and fed once daily at 7:30 am, a-c: different letters on the same line are statistically different, PF/HC: pelvic fat/hot carcass, $\mathrm{L}^{*}$ : lightness, $\mathrm{a}^{*}$ : redness, $\mathrm{b}^{*}$ : yellowness, $\mathrm{C}^{*}$ : chroma values, $\mathrm{H}^{*}$ : hue value 
Table 3 Correlation coefficients among the carcass values studied in the study

\begin{tabular}{|c|c|c|c|c|c|c|c|c|c|c|}
\hline & $\mathrm{DF}$ & Conf & MS & LDA & FT & $\mathrm{pH}$ & $\mathrm{L}^{*}$ & $a^{*}$ & $b^{*}$ & $\mathrm{C}^{*}$ \\
\hline Conf & -0.013 & & & & & & & & & \\
\hline MS & $0.632^{* *}$ & 0.728 & & & & & & & & \\
\hline LDA & -0.122 & 0.381 & 0.278 & & & & & & & \\
\hline FT & 0.210 & -0.217 & 0.143 & -0.089 & & & & & & \\
\hline $\mathrm{pH}$ & 0.168 & -0.212 & 0.140 & 0.037 & -0.141 & & & & & \\
\hline CL & $0.393^{*}$ & $0.576^{* *}$ & $0.618^{* * *}$ & $0.413^{*}$ & -0.123 & -0.118 & & & & \\
\hline YG & $0.447^{*}$ & -0.114 & 0.220 & $-0.774^{* *}$ & $0.428^{*}$ & -0.126 & & & & \\
\hline $\mathrm{L}^{*}$ & 0.144 & $-0.461^{*}$ & 0.150 & 0.092 & 0.343 & -0.140 & & & & \\
\hline$a^{*}$ & 0.031 & -0.245 & -0.057 & -0.034 & -0.240 & -0.009 & $-0.217^{* *}$ & & & \\
\hline$b^{*}$ & 0.010 & $-0.500^{*}$ & -0.143 & -0.049 & -0.140 & $0.358^{*}$ & -0.094 & $0.732^{* *}$ & & \\
\hline $\mathrm{C}^{*}$ & 0.037 & -0.275 & -0.063 & -0.042 & -0.242 & 0.046 & $-0.202^{* *}$ & $0.993^{* *}$ & $0.807^{* *}$ & \\
\hline $\mathrm{H}^{*}$ & -0.237 & 0.131 & -0.099 & 0.028 & 0.358 & -0.265 & 0.128 & $-0.439^{* *}$ & $-0.836^{* *}$ & $-0.514^{* *}$ \\
\hline
\end{tabular}

Conf: conformation, MS: marbling scor, LDA: LD area, FT: Fat thickness over Longissimus Dorsi, CL: carcass length, YG: yield grade, DF: Degree of fatten, **:P<0.01, *: $\mathrm{P}<0.05, \mathrm{~L}^{*}$ : lightness, $\mathrm{a}^{*}$ : redness, $\mathrm{b}^{*}$ : yellowness, $\mathrm{C}^{*}$ : chroma values, $\mathrm{H}^{*}$ : hue value

The G1 produced a higher amount of pelvic fat $(3.5 \%$ of the warm carcass) than the other groups and the G5 have at the lowest. This ratio is in line with international standards (Anonymous, 2002). The G3 (by age groups) and G5 (by all groups) made less pelvic fat since they had chance to move freely in the paddocks (Table 2). Carcass of younger and more movely EAR bulls is characterized by lower pelvic fat. The findings are higher than values reported by Yüksel et al. (2012) and are a lower than Hollo et al. (2012).

The degree of fatting is an indigator in terms of effective use of ration and time. Although the G1 was found to be "average", the other groups had a "slight" structure. It is consistent with previous observations (Mezgebo et al., 2017). The higher degree of fatten in the G1 bulls was due to their feeding style and the in the study may be expect it is more directly related to housing and age differences, given that all animals were exposed to the same environmental conditions. Although degree of fatten did not have significant influence on conformation, LD area, fat thickness over LD and colour parameters were significantly affected by the marbling score. In $\mathrm{pH}$, marbling, fat thickness over LD and colour parameters a positive correlation with degree of fatten was observed for marbling score it was significant and for LD area and conformation were negative. It may be stated, that in case of higher degree of fatten, beef meat is characterized by richer marbling scor and this fact may influence general beef quality, however, no correlation between degree of fatten and conformation was observed.

European beef producers are paid based on the weight of the animals at slaughter and on carcass conformation and fat cover scores (Tarres et al., 2011). The G3 had a higher value in terms of conformation, even though it had have lower scorer than the bulls in the same age group in terms of factors such as pelvic fat and degree of fatten. The bulls in this group were fattened in a larger and less stressful environment. The similar situation were also seen in the G5 group. The G3 group have got a score between "good" and "very good". This result is similar with findings of Mezgebo et al. (2017). On the other hand, while G1 and G5 take a value between "fair" and "good", G4 is between "poor" and "fair". The G1 group showed similarity with results reported by Berthiaume et al. (2006).
It is detected similarity that G2 group are similarity with findins of Yüksel et al. (2012) (for PF group) and Koonawootrittriron et al. (2011). Conformation may vary depending on the physiological status, genotype and feeding style of animals. Nogalski et al. (2018) determined, similar with our results, the value of the carcass conformation for milk feeder and nurse cow groups as medium ( 7 nearly). It did not observe any difference between in the conformation scores of the postweaning and finishing periods in Nuella cattle (Cancian et al., 2014). Litwinczuk et al. (2012) reported the highest conformation score in Limousin bulls. The findings of these authors are higher than our results.

The marbling score is the strongest beef quality parameter for the carcasses evaluation in many countries (Hocquette et al., 2005). The treatment groups had divided into two groups in terms of marbling score. The G1 had the highest result in terms of marbling score in groups. The findings showed different from notices of Hollo et al. (2012) and Roberts et al. (2009). The result found for the G3 were similar to notice reported by Yüksel et al. (2009), There is a positive relationship between marbling score and conformation. This result has also been confirmed by Park et al. (2002).

The LD area is a factor that can be affected by the some factors. It was found that the carcass conformation class be efficient on LD area in different genotypes (Nogalski et al., 2013). Significant influence of nutrition style on the area of $\mathrm{LD}$, which was observed, is consistent with the statement that LD area is influenced by nutrition style (Yüksel et al., 2009). Hanwoo bulls fed according to the classical method had been characterized by wider LD area (Chung et al., 2017). Cancian et al. (2014) reported that LD area was larger in non-castrated Nellore bulls. Our research team determined that there is a positive relationship between fattening in free paddock outside and LD area in this study. It may be concluded that LD area can be influenced by factors such as feeding style, ration composition, physiological position of the animal.

In present study, it observed that feeding style and housing conditions caused to carcass fat thickness differences. The G2 was found to have higher values than other groups because of different feeding style (G1, G4), housing conditions (G3, G5) and age (G4). The G3 that 
has much movement chance have lower values than other groups. In general, the present study is differ to a study of Yüksel et al. (2009) who reported that fat thickness over LD were not differ among control, $4 \%$ SBP, $8 \%$ sugar beet pulp (SBP). A study reported back fat thickness for concentrate with roughage separately $(\mathrm{CON})$ and total mixed ration (TMR) modals in Hanwoo steers 11.95, 13.95 respectively (Chung et al., 2017). The present results suggest that gaining optimum fat thickness over LD may be useful assigning specific feeding style and housing condition according to age.

The yield grade values of our study are close to 1 or 2 values. This is an important result. Because, the lower the numerical value of the USDA yield grade, the higher the expected yield of closely trimmed, boneless retail cuts. Thus a yield grade 1 carcass provides the greatest amount of saleable beef while a yield grade 5 is the lowest-yielding carcass (Anonymous, 2013). According to our findings, yield grade didn't differ among treatment groups. It may be concluded that no differences in yield grade were observed of EAR bulls feeded at differ age and in housing condition $(\mathrm{P}>0.05)$. Our findings aren't consistent with previous observations (Chung et al., 2017; Yüksel et al., 2012; Yüksel et al., 2009) who reported higher value for yield grade.

Among the carcass characteristics were found correlated in different levels such as high, medium, low or positive, negative. Correlations among conformation, marbling score, LD area, fat thickness over LD, degree of fatten were moderate ( $\mathrm{R}$ coefficient lower than 0.7 ), so it may be suggested that any of these values is not the factor influencing analysed beef features. Our findings are different from the reports of Yüksel et al. (2012).

In the study, $\mathrm{pH}$ values became apparent within the first $24 \mathrm{~h}$ after slaughter. The most variable factors that may also influence meat quality in the meat production are the weight of animal and pH of meat (Guzek et al., 2013). The meat $\mathrm{pH}$ of an unstressed animal is range from 5.4 to 5.7 (Page et al., 2001). These ratios are considered normal range. The $\mathrm{pH}$ values for our study are range 5.65-5.80. Mezgebo et al. (2017) reported similar results for early and late breeds in $48 \mathrm{~h}$. Page et al. (2001) had found that longissimus muscle $\mathrm{pH}$ of 5.87 was the approximate cutoff between normal and dark-cutting carcasses. The $\mathrm{pH}$ value for $24 \mathrm{~h}$ reported by Nogalski et al. (2013) for different conformation classes is lower than our findings. Normal values of $\mathrm{pH}$ may be attributed that for the meat color was not adverse affected the bulls were transported to slaughterhouse stress-free manner. The correlations between carcass conformation and meat colour characteristics estimated by Weglarz (2011) were lower than those obtained in the present study.

Carcass measurements, especially the carcass length, are important since they affect the amount of precious muscles. A positive correlation in among conformation, LD area, marbling score and degree of fatten with the carcass length was observed - for carcass length it was significant these correlations. It may be stated, that in case of higher carcass length value, EAR cattle meat can characterized by richer marbling score, wider LD area, moderate degree of fatten, fitting conformation and this fact may influence general beef quality, excluding fat thickness over LD. On this matter, the authors reported different opinions. Although the feeding style is similar, it has been reported that the carcass length may vary according to the genotype (Litwinczuk et al., 2012). It was reported (Zhang et al., 2016) that the carcass length measures detected in a study with Yak had be higher than findings belonging to this study but the width of round and length round were lower from them. Pazdiora et al. (2013) reported also lower values than our results for the carcass length.

In this study, in carcass quality traits, $L^{*}$ value found significantly lower in the bulls G1, G2 and G3 groups than those G4 and G5 without affecting the other meat color parameters $\left(b^{*}, C^{*}\right)$ among all groups. This result might be attributed to age and to feeding at lower temperatures during fattening periods. It is confirmed by observations of Weglarz (2010) who found higher values of $\mathrm{L}^{*}$ in the winter season for all cattle categories, excluding meat of cows. Some authors have also reported that the parameter $\mathrm{L}^{*}$ might varied according to the feeding model. $\mathrm{L}^{*}$ colour score was found lower in Hanwoo bulls fed concentrates with straw (Chung et al., 2017). In components of colour, it was significantly negative correlated $\mathrm{a}^{*}, \mathrm{c}^{*}$ with $\mathrm{L}^{*}$. On the other hand among $\mathrm{L}^{*}, \mathrm{~b}^{*}$ with conformation, and $\mathrm{pH}$ with $b^{*}$ was observed negative correlation. In spite of $\mathrm{L}^{*}$ differences, no $b^{*}$ and $\mathrm{C}^{*}$ differences were observed in the groups. The authors reported different results according to the characteristics of the treatment material in this matter. Lightness was affected by the interaction between gender and genotip and breed of animals, and $\mathrm{L}^{*}$ became higher in Charolais $\times$ Simmental bulls and heifers (Bures and Barton, 2012) but not in Holstein bulls based on forage diet (Catrileo et al., 2014) than our results. On the other hand, The L* values of the study conducted by Weglarz (2010) had similar to the G1, G2, G3 groups but found to be lower than G4, G5. The G4 and G5 groups had a more lightness colour. This result may be connected with the fact that are not negative effect of the housing conditions that is resulted from the younger animals. Older animals were characterized by lower values of a* component of colour (Guzek et al., 2013). This case is confirmed by Weglarz, 2010, that a less red colour of meat is obtained from older bulls rather than from younger. However, EAR bulls usually have high value red meat (Yüksel et al., 2012). As a matter of fact, our findings confirm this case. Belonging our results $\mathrm{a}^{*}$ parameter was higher than findings by reported Marti et al. (2013). On the other hand, the $\mathrm{C}^{*}$ parameter were found to be lower than the Mezgebo et al. (2017) findings. At the surface of meat, myoglobin in contact with air is oxygenated and exhibits a bright red colour (Geaye et al., 2001). Brisket muscles have not as depths other some muscles of the carcass (such as round). Therefore, it isn't observed much different between intramuscular colour change and extra muscular colour change in this muscle. Thus, display of meat and shelf life can be longer.

\section{Conclusion}

The present study has shown differences among groups at feeding style, house condition, and two fixed ages in relation to pelvic fat, degree of fatten, conformation, fat thickness over LD. The groups $24 \mathrm{~m}$ old, had a higher pelvic fat, and LD area than $12 \mathrm{~m}$ old. However the groups 
$12 \mathrm{~m}$ old, had a higher $\mathrm{L}^{*}$ value than $24 \mathrm{~m}$ old. Although groups in terms of fat thickness are statistically similar (except G2), G5 could be considered advantageous than other.

\section{Acknowledgements}

This study was funded by specific budget of the Eastern Anatolian Agricultural Research Institute of Turkey.

\section{References}

Anonymous.2002. Understanding Beef Carcass Data Reports, Educational programs of the Kentucky Cooperative Extension Service. University of Kentucky-College of Agriculture,www.ca.uky.edu.

Anonymous. 2013.Understanding Yield Grades and Quality Grades for Value-Added Beef Producers and Marketers. University of Tennessee Institute of Agriculture, extension SP755, https://ag.tennessee.edu/cpa/CPA\%20Publications/SP755.pdf

Berthiaume R, Mandell I, Faucitano L, Lafreniere C. 2006. Comparison of alternative beef production systems based on forage finishing or grain-forage diets with or without growth promotants: 1. Feedlot performance, carcass quality, and production costs. J. Anim. Sci., 84:2168-2177.

Boggs DL, Merkel RA. 1984. Live animal carcass evaluation and selection manual (2nd ed.). Dubuque, Iowa, USA: Kendal Hunt Publishing Company.

Bures D, Barton L.2012. Growth performance, carcass traits and meat quality of bulls and heifers slaughtered at different ages. Czech J. Anim. Sci.,57,1: 34-43.

Catrileo A, Morales R, Rojas C, Cancino D. 2014. Beef production from dairy bulls under two different production systems and its effect on the fatty acid profile and beef quality. Chilean J. Agric. Res., 74, 3.

Cancian PH, Gomes RC, Manicardi FR, Ianni AC, Bonin MN, Leme PR, Silva SL. 2014.Correlations of visual scores, carcass traits, feed efficiency and retail product yield in Nellore cattle. Sci. Agric,71, 1: 17-22.

Chung CS, Cho WK, Jang IS, Lee SS, Moon YH. 2017. Effects of feeding system on growth performance, plasma biochemical components and hormones, and carcass characteristics in Hanwoo steers.Asian-Australas $\mathbf{J}$ Anim. Sci., 30, 8:1117-1123.

FAO. 2017. Food and Agriculture Organization of the United Nations. http://www.fao.org/faostat/en/?\#data/

Geaye Y, Baucharta D, Hocquettea JF, Culıol J.2001. Effect of nutritional factors on biochemical, structural and metabolic characteristics of muscles in ruminants, consequences on dietetic value and sensorial qualities of meat, Repd. Nutr. Dev., 41:1-26.

Guzek D, Głąbska D, Pogorzelski G, Kozań K, Pietras J, Konarska M, Sakowska A, Glabski K, Pogorzelska E, Barszczewski J, Wierzbicka A. 2013.Variation of Meat Quality Parameters Due to Conformation and Fat Class in Limousin Bulls Slaughtered at 25 to 27 Months of Age. Asian Australas. J. Anim. Sci.,26, 5: 716-722.

Hocquette JF, Richardson RI, Prache S, Medale F, Duffy G, Scollan ND. 2005. The future trends for research on quality and safety of animal products. Ital. J. Anim. Sci., 4:49-72.

Hollo G, Nuernberg K, Somogyi T, Anton I, Hollo I.2012. Comparison of fattening performance and slaughter value of local Hungarian cattle breeds to international breeds Archiv Tierzucht, 55, 1: 1-12.

Honikel KO. 1998. Reference methods for the assessment of physical characteristics of meat. Meat Science,49: 447-457.
Koonawootrittriron S, Elzo MA, Kankaew C, Osothongs M.2011. Factors affecting carcass weight, dressing percent, and marbling score of crossbred beef cattle in tropical Thailand, http://animal.ifas.ufl.edu/elzo/presentations/regular/docs/201 1 10_koon awootrittriron.pdf

Kryza A. 2013. The Steak Breakdown: Your Ultimate Guide To Cuts Of Beef. https://www.thrillist.com/eat/nation/ultimatesteak-guide-how-to-cook-a-steak

Kukowski AC, Maddock RJ, Wulf DM.2004. Evaluating consumer acceptability of various muscles from the beef chuck and rib. Journal Animal Science,82: 521-525.

Kunkle WE, Sand RS, Rae DO.1994. Effect of body condition on producduvity in beef cattle. Factors Affecting Calf Crop, CRC pres LLC, p: 167-178.

Litwińczuk Z, Chabuz W, Domaradzki P, Jankowski P. 2012. Slaughter value of young Polish Black-and-White, Whitebacked, Polish Holstein-Friesian and Limousin bulls under semiintensive fattening. Ann. Anim. Sci., Vol. 12, No. 2: 159-168.

Marti S, Realini CE, Bach A, Perez-Juan M, Devant M. 2013. Effect of castration and slaughter age on performance, carcass, and meat quality traits of Holstein calves fed a highconcentrate diet. J. Anim. Sci., 91: 1129-1140.

Mezgebo GB, Monahan FJ, McGee M, O’Riordan EG, Picard B, Richardson RI, Moloney RI. 2017. Biochemical and organoleptic characteristics of muscle from early and late maturing bulls in different production systems. Animal,11,9: 1636-1644.

Nogalski Z, Pogorzelska-Przybyłek P, Sobczuk-Szul M, Purwin C, Modzelewska-Kapituła M. 2018. Effects of rearing system and feeding intensity on the fattening performance and slaughter value of young crossbred bulls. Ann. Anim. Sci., Vol. 18, No. 3: 835-847.

Nogalski Z, Wroński M, Wielgosz-Groth Z, Purwin C, SobczukSzu M, Mocho M, Pogorzelska P. 2013. The effect of carcass conformation class (EUROP system) on the slaughter quality of young crossbred beef bulls and Holstein-Friesians. Ann. Anim. Sci., Vol. 13, No. 1: 121-131.

Page JK, Wulf DM, Schwotzer TR. 2001. A survey of beef muscle color and $\mathrm{pH}$. J. Anim. Sci,79:678-687.

Park GB, Moon SS, Ko YD, Ha JK, Chang HH, Joo ST.2002. Influence of slaughter weight and sex on yield and quality grades of Hanwoo carcasses. J. Anim. Sci.80:129-136.

Pazdiora RD, Resende FD, Faria MH, Siqueira GR, Souza Almeida GB, Sampaio RL, Pacheco PS, Prietto MSR. 2013.Animal performance and carcass characteristics of Nellore young bulls fed coated or uncoated urea slaughtered at different weights, R. Bras. Zootec., 42; 4: 273-283.

Roberts SD, Kerth CR, Braden KW, Rankins Jr DL, KrieseAnderson L, Prevatt JW. 2009. Finishing steers on winter annual ryegrass (Lolium multiflorum Lam.) with varied levels of corn supplementation I: Effects on animal performance, carcass traits, and forage quality, J. Anim. Sci.,87:2690-2699.

Ritchie H, Roser M.2018. Meat and Seafood Production \&Consumption. https://ourworldindata.org/meat-andseafood-production-consumption

SPSS. 2015. SPSS for windows. Released 20.0 SPSS Inc., Chicago, IL., USA.

Tarres J, Fina M, Varona L, Piedrafita J. 2011. Carcass conformation and fat cover scores in beef cattle: A comparison of threshold linear models vs grouped data models, Genetics Selection Evolution, 43:16.

USDA. 1989. Official United States standards for grades of carcass beef. Agricultural Marketing Service (USDA, Washington DC).

Weglarz A. 2010. Meat quality defined based on pH and colour depending on cattle category and slaughter season. Czech J. Anim. Sci.,55, 12: 548-556. 
Weglarz A. 2011. Effect of pre-slaughter housing of different cattle categories on beef quality, Animal Science Papers and Reports, 29, 1: 43-52.

Yüksel S, Sezgin E, Kopuzlu S. 2011. Some of Common Features Of Eastern Anatolian Red Cattle, Its Local Position And Importance As Genetic Resources. 8 th Global Conference On The Conservation Of Animal Genetic Resources, 4-8 October, Tekirdag, Turkiye.

Yüksel S, Yanar M, Aksu MI, Kopuzlu S, Kaban G, Sezgin E, Oz F. 2012. Effects of different finishing systems on carcass traits, fatty acid composition, and beef quality characteristics of young Eastern Anatolian Red bulls. Trop Anim Health Prod., 44:1521-1528.
Yüksel S, Yanar M, Turgut L, Özlütürk A, Kopuzlu S, Sezgin E.2009. Feed efficiency and carcass and meat quality characteristics of bulls finished on diets containing varied proportions of wheat straw and wet sugar beet pulp.S. African J. Anim. Sci. 39, 4.

Zhang L, Sun B, Yu Q, Ji Q, Xie P, Li H, Wang L, Zhou Y, Li Y, Huang C, Liu X. 2016. The breed and sex effect on the carcass size performance and meat quality of Yak in different muscles. Korean J. Food Sci.,36, 2: 223 229. 